\title{
Modeling, Evaluating and Scaling up a Commercial Multilayer Claus Converter Based on Bench Scale Experiments
}

\author{
Sepehr Sadighi*, Seyed Reza Seif Mohaddecy, Mehdi Rashidzadeh \\ ${ }^{1}$ Catalysis Development Technologies Division, Research Institute of Petroleum Industry (RIPI), West \\ Side of Azadi Complex, Tehran, P.O. Box 1485733111, Iran. \\ ${ }^{2}$ Gas Processing Institute (GPI), Research Institute of Petroleum Industry (RIPI), West Side of Azadi \\ Complex, Tehran, P.O. Box 1485733111, Iran.
}

Received: $6^{\text {th }}$ April 2020; Revised: 23rd May 2020; Accepted: 25 th May 2020; Available online: $30^{\text {th }}$ July 2020; Published regularly: August 2020

\begin{abstract}
Industrial scale reactors work adiabatically and measuring their performance in an isothermal bench scale reactor is faced with uncertainties. In this research, based on kinetic models previously developed for alumina and titania commercial Claus catalysts, a multilayer bench scale model is constructed, and it is applied to simulate the behavior of an industrial scale Claus converter. It is shown that performing the bench scale isothermal experiments at the temperature of $307^{\circ} \mathrm{C}$ can reliably exhibit the activity of catalytic layers of an industrial Claus converter operating at the weighted average bed temperature (WABT) of $289^{\circ} \mathrm{C}$. Additionally, an adiabatic model is developed for a target industrial scale Claus reactor, and it is confirmed that this model can accurately predict the temperature, and molar percentages of $\mathrm{H}_{2} \mathrm{~S}$ and $\mathrm{CS}_{2}$. Based on simulation results, $20 \%$ of excess amount of Claus catalysts should be loaded to compensate their deactivation during the process cycle life. Copyright $\mathbb{C}$ 2020 BCREC Group. All rights reserved
\end{abstract}

Keywords: Sulfur recovery plant; Claus converter; Catalyst evaluation; Kinetic modeling; Scale up

How to Cite: Sadighi, S., Mohaddecy, S.R.S., Rashidzadeh, M. (2020). Modeling, Evaluating and Scaling up a Commercial Multilayer Claus Converter Based on Bench Scale Experiments. Bulletin of Chemical Reaction Engineering \& Catalysis, 15(2), 465-475 (doi:10.9767/bcrec.15.2.7521.465-475)

Permalink/DOI: https://doi.org/10.9767/bcrec.15.2.7521.465-475

\section{Introduction}

$\mathrm{H}_{2} \mathrm{~S}$ (hydrogen sulfide) and carbon-sulfur components (such as $\mathrm{CS}_{2}$ and $\mathrm{COS}$ ) are toxic byproducts of refining natural gas and crude oil, and therefore, their entrance in any exhaust gas is under stiff environmental regulations [1,2]. To tackle with this issue, the modified sulfur re-

* Corresponding Author.

Email: sadighis@ripi.ir (S. Sadighi) covery unit (SRU) is cherished to convert $\mathrm{H}_{2} \mathrm{~S}$ and carbon-sulfur compounds coming from the exhaust of those industries to the elemental sulfur $[3,4]$. The modified Claus process is conducted at two steps including thermal and catalytic stages [5]. The catalytic reactors of a SRU is usually loaded by alumina $\left(\mathrm{Al}_{2} \mathrm{O}_{3}\right)$ and titania $\left(\mathrm{TiO}_{2}\right)$ Claus catalysts (combined bed or multilayer configuration) to promote the following reactions [6,7]: 


$$
\begin{aligned}
& 2 \mathrm{H}_{2} \mathrm{~S}+\mathrm{SO}_{2} \leftrightarrow 2 \mathrm{H}_{2} \mathrm{O}+\frac{3}{n} \mathrm{~S}_{n}, \Delta H=-11.85 \mathrm{kcal} / \mathrm{mol} \\
& \mathrm{CS}_{2}+2 \mathrm{H}_{2} \mathrm{O} \rightarrow 2 \mathrm{H}_{2} \mathrm{~S}+\mathrm{CO}_{2}, \Delta H=4.54 \mathrm{kcal} / \mathrm{mol} \\
& \mathrm{CS}_{2}+\mathrm{SO}_{2} \rightarrow \mathrm{CO}_{2}+\frac{3}{n} \mathrm{~S}_{n}, \Delta H=-12.9 \mathrm{kcal} / \mathrm{mol}
\end{aligned}
$$

Industrial scale reactors usually work adiabatically, and they are essentially different from bench or even pilot scale reactors. In the former, there is a temperature profile along the catalytic bed whereas in the latter a constant temperature governs the whole bed. There are many literatures that tried to model a laboratory or bench scale and an industrial scale Claus reactor (called catalytic converter). Kerr et al. devoted a research on developing a kinetic model for the modified Claus reaction (Equation 1) in a laboratory scale device, and they estimated kinetic parameters for the Arrhenius form of its reaction rate [8]. In the other works, these researches developed a kinetic model for $\mathrm{COS}$ and $\mathrm{CS}_{2}$ hydrolysis reactions [9], and then tried to find a deactivation mechanism for the Claus catalysts in a laboratory scale reactor [10].

Mendioroz et al. studied the kinetic of modified Claus process on $\gamma$-alumina at low temperature $\left(100-200^{\circ} \mathrm{C}\right)$ in a bench scale device [11]. To develop Langmuir type expression for the main Claus reaction, experiments were carried out at the different $\mathrm{SO}_{2}$ and $\mathrm{H}_{2} \mathrm{~S}$ concentrations. The results showed the chemical reaction between adsorbed species, such as $\mathrm{H}_{2} \mathrm{~S}$ as the controlling step of the process. Nedez and Ray tried to comprehend mechanisms involved in the deactivation of Claus catalysts based on the bench scale experiments [12]. In this research, a feed containing $\mathrm{H}_{2} \mathrm{~S}, \mathrm{SO}_{2}, \mathrm{H}_{2} \mathrm{O}$ and $\mathrm{CS}_{2}$ was used, and $\mathrm{O}_{2}$ was injected as a deactivation agent. They discovered that the main cause of the deactivation for the Claus alumina catalyst was the sulphation of its surface, and it could tremendously affect the activity of the catalyst versus time of the operation. Zagoruiko and Matros [13] proposed a mathematical model for the main Claus reaction carrying out in a catalytic reactor under conditions of sulfur condensation. To construct the model, a Langmuir type expression was successfully used, and based on simulation results, a reverse flow was recommended to regenerate the catalytic bed which was deactivated by the accumulation of sulfur inside pores of the catalyst.

Gemmingen and Lahne developed a kinetic model for a Linde Clinsulf process for the sulfur recovery, and they only included main
Claus reaction and hydrolysis of COS in their model [14]. The required kinetic parameters were estimated from chemical equilibrium of each reaction according to the mass conservation law and temperature-dependent equilibrium constants. In the other research, Abedini et al. proposed a model for rapid estimation of the produced sulfur in converters of Claus process. To simplify the model, they only considered the main Claus reaction [15]. Nabikandi and Fatemi developed a kinetic model for an industrial scale SRU unit in which main Claus reaction and hydrolysis of $\mathrm{CS}_{2}$ and COS compounds were included [16]. They recommended that using kinetic based equations for simulating SRU was more accurate than using equilibrium (Gibbs free energy minimization) modeling approach. Ghahraloud et al. built a thermal model and catalytic sections of a commercial scale SRU loaded with alumina catalyst based on kinetic parameters reported in the literature. They concluded that s kinetic model could be successfully used to simulate the output variables of the target SRU.

Moreover, in the other research accomplished by these authors, this proposed kinetic model was utilized to simulate the sulfur emission of a SRU [18]. Based on simulations results, it was recommended that by implementing isothermal reactors instead of adiabatic convertors, less $\mathrm{H}_{2} \mathrm{~S}$ emission (about 1.8\%) was achievable. In this respect, Sadighi and Mohaddecy used the solid package of Aspen plus for simulating and optimizing inlet temperatures of SRU convertors [19]. By comparing simulation results with data obtained from the under study unit, it was confirmed that using Aspen plus was reliable for optimizing temperatures of Claus convertors, especially when the corresponding kinetic constants of the loaded commercial catalysts in the convertors of SRU were not available.

The aim of this research is to evaluate the performance of an industrial Claus converter by using data obtained from isothermal bench scale experiments. To emulate behaviors of a Claus converter in terms of $\mathrm{H}_{2} \mathrm{~S}$ and $\mathrm{CS}_{2}$ conversions, a multilayer Claus model is developed. Next, by using this combined bed model, the bed temperature for carrying out bench scale experiments is proposed such that the behavior of the Claus converter can be imitated. Thereafter, an adiabatic model is developed, and it is applied to scale up a bench scale reactor to an industrial Claus convertor. Outputs of this model are validated versus the actual data gathered from a commercial SRU. 


\section{Materials and Methods}

2.1 Process Description of the Understudy Industrial Scale Claus Unit

A block flow diagram of the understudy Claus process unit is presented in Figure 1. As seen, the acid gas from the upstream is directed to the acid gas KO drum D-101. The exhaust gas from this drum is warmed up to 220 ${ }^{\circ} \mathrm{C}$ in the E-106 by using HP steam, and then it is conducted through the reaction furnace $(\mathrm{H}-$ 101). The following reaction is carried out in this unit:

$$
\mathrm{H}_{2} \mathrm{~S}+\frac{3}{2} \mathrm{O}_{2} \rightarrow \mathrm{SO}_{2}+\mathrm{H}_{2} \mathrm{O}
$$

The process gas leaving the gas cooler (B$101)$ is entered to the first catalytic reactor (R101) with the temperature and pressure of about $250{ }^{\circ} \mathrm{C}$ and 1.34 barg, respectively. In this reactor, sulfur is produced, and thereafter it is trapped. Due to the exothermic nature of Claus reactions, the temperature increases across the catalytic bed. However, the inlet temperature of the reactor should be adjusted such that its outlet temperature reaches about $310{ }^{\circ} \mathrm{C}$ for hydrolyzing $\mathrm{COS}$ and $\mathrm{CS}_{2}$ compounds. The hot gases leaving the first reactor are cooled in a condenser (E-104) by generating LP steam. The condensed sulfur is also sent to the sulfur degassing pit (T-101). The output stream of the first Claus reactor is conducted to the second and third converters to further con- version of $\mathrm{H}_{2} \mathrm{~S}$ and $\mathrm{SO}_{2}$. The first Claus reactor is loaded with separate layers of $\mathrm{Al}_{2} \mathrm{O}_{3}$ and $\mathrm{TiO}_{2}$ catalysts at its top and bottom, respectively. The gas hourly space velocities (GHSV) of these layers are about $1050 \mathrm{~h}^{-1}$ and $2100 \mathrm{~h}^{-1}$, respectively. For the understand Claus converter, the mass of $\mathrm{Al}_{2} \mathrm{O}_{3}$ and $\mathrm{TiO}_{2}$ catalysts loaded in the top and bottom layers of the catalytic bed are equal to $17900 \mathrm{~kg}$ and $12780 \mathrm{~kg}$, respectively.

\subsection{Experiments in the Bench Scale System}

Experiments were carried out in a bench scale plant designed and constructed by Research Institute of Petroleum Industry (RIPI, Iran) for the purpose of studying the catalytic section of the Claus process. The flow diagram of this unit is presented in Figure 2. The reactor is a tube with the inside diameter of $16 \mathrm{~mm}$ and total length of $2160 \mathrm{~mm}$. For both $\mathrm{Al}_{2} \mathrm{O}_{3}$ and $\mathrm{TiO}_{2}$ catalysts, the first layer (length of 30

Table 1. Specifications of the Claus catalysts studied [20].

\begin{tabular}{lccc}
\hline \multicolumn{1}{c}{ Specification } & Unit & $\mathrm{Al}_{2} \mathrm{O}_{3}$ & $\mathrm{TiO}_{2}$ \\
\hline Color & - & white & white \\
Shape & - & Pellet & Bead \\
Size & $\mathrm{mm}$ & $3-6$ & $3-4$ \\
Density & $\mathrm{kg} / \mathrm{m}^{3}$ & 680 & 980 \\
Strength & $\mathrm{N} / \mathrm{cm}$ & $>12$ & $>70$ \\
Specific surface & $\mathrm{m}^{2} / \mathrm{g}$ & $300-400$ & $>100$ \\
\hline
\end{tabular}
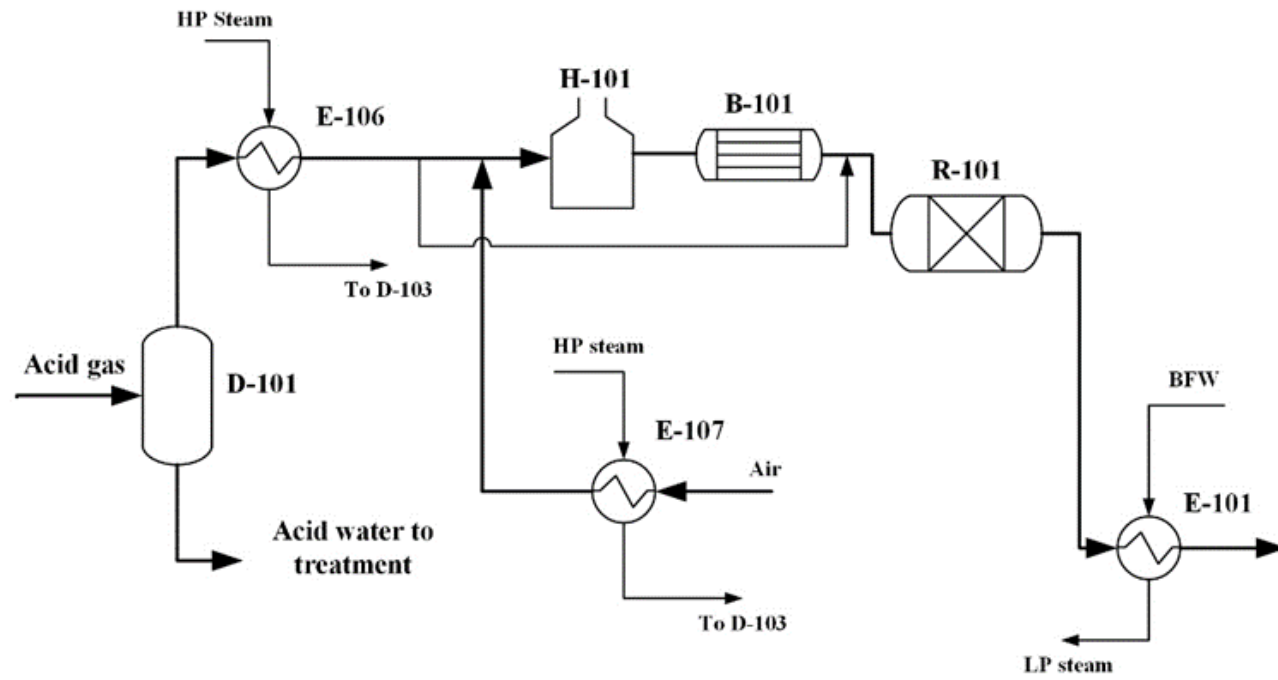

B-101: Gas cooler

BFW: Boiler feed water

D-101, D-103: Acid gas knock out drums

E-101, E-104, E-106, E-107: Heat exchangers

HP steam: High pressure steam
H-101: Reaction furnace

LP steam: Low pressure steam

R-101: First catalytic reactor

R-102: Second catalytic reactor

Figure 1. Block flow diagram of the target Claus unit. 
$\mathrm{mm}$ ) is filled with inert $\alpha-\mathrm{Al}_{2} \mathrm{O}_{3}$ beads to obtain a uniform flow and temperature. The middle layer is loaded with the catalyst mixed with the equal volume of quartz particles, and the remained volume of the reactor is charged with $\alpha-\mathrm{Al}_{2} \mathrm{O}_{3}$ particles. The specifications of the Claus catalysts are presented in Table 1 . It should be mentioned that catalysts studied in this apparatus were the same types as used in the commercial scale Claus converter.

In this unit, temperature along the catalytic bed is adjusted by using five temperature indicators and controllers (TIC). Additionally, a gas chromatograph (GC) with the thermal conductivity detector (TCD) and using helium as a carrier gas is applied to analyze the various species in the feed and product (i.e. $\mathrm{N}_{2}, \mathrm{H}_{2} \mathrm{~S}$, $\mathrm{SO}_{2}$ and $\mathrm{CS}_{2}$ ). By using mass flow controllers (MFCs) and a micro pump for injecting water, feed ingredients of the bench scale reactor are set on values similar to those of a Claus converter. However, due to limitations in the gas analyzing system, carbonyl sulfide (COS) and carbon disulfide $\left(\mathrm{CS}_{2}\right)$ are lumped into a single compound i.e. $\mathrm{CS}_{2}$. Similarly, $\mathrm{CO}_{2}$ and $\mathrm{N}_{2}$ are lumped into $\mathrm{N}_{2}$ component. According to the mentioned assumptions, the feed composition is adjusted to the values close to the industrial scale plant (Table 2).
To carry out experiments, the bench scale reactor is loaded with $26.5 \mathrm{~cm}^{3}$ and $13.5 \mathrm{~cm}^{3}$ of $\mathrm{Al}_{2} \mathrm{O}_{3}$ and $\mathrm{TiO}_{2}$ catalysts, respectively. To mitigate the effect of the wall and diminish the axial dispersion and back mixing phenomena, both catalysts were diluted with the equal volume of quartz. It is obvious that the GHSV of the catalytic bed can be regulated by manipulating the rate of the gases and water injected by MFCs and micro pump, respectively.

\subsection{Developing Kinetic Models for the Claus} Reactor

2.3.1 Kinetic model of the bench scale Claus reactor

Kinetic models of the studied Claus reactor were previously described in detail [20], and it

Table 2. Feed composition of the multi-layer catalytic bed.

\begin{tabular}{cc}
\hline Compound & Mol\% \\
\hline $\mathrm{CS}_{2}+\mathrm{COS}$ & 2.05 \\
$\mathrm{H}_{2} \mathrm{O}$ & 25.24 \\
$\mathrm{H}_{2} \mathrm{~S}$ & 3.61 \\
$\mathrm{SO}_{2}$ & 2.86 \\
$\mathrm{~N}_{2}$ & Balanced \\
\hline
\end{tabular}

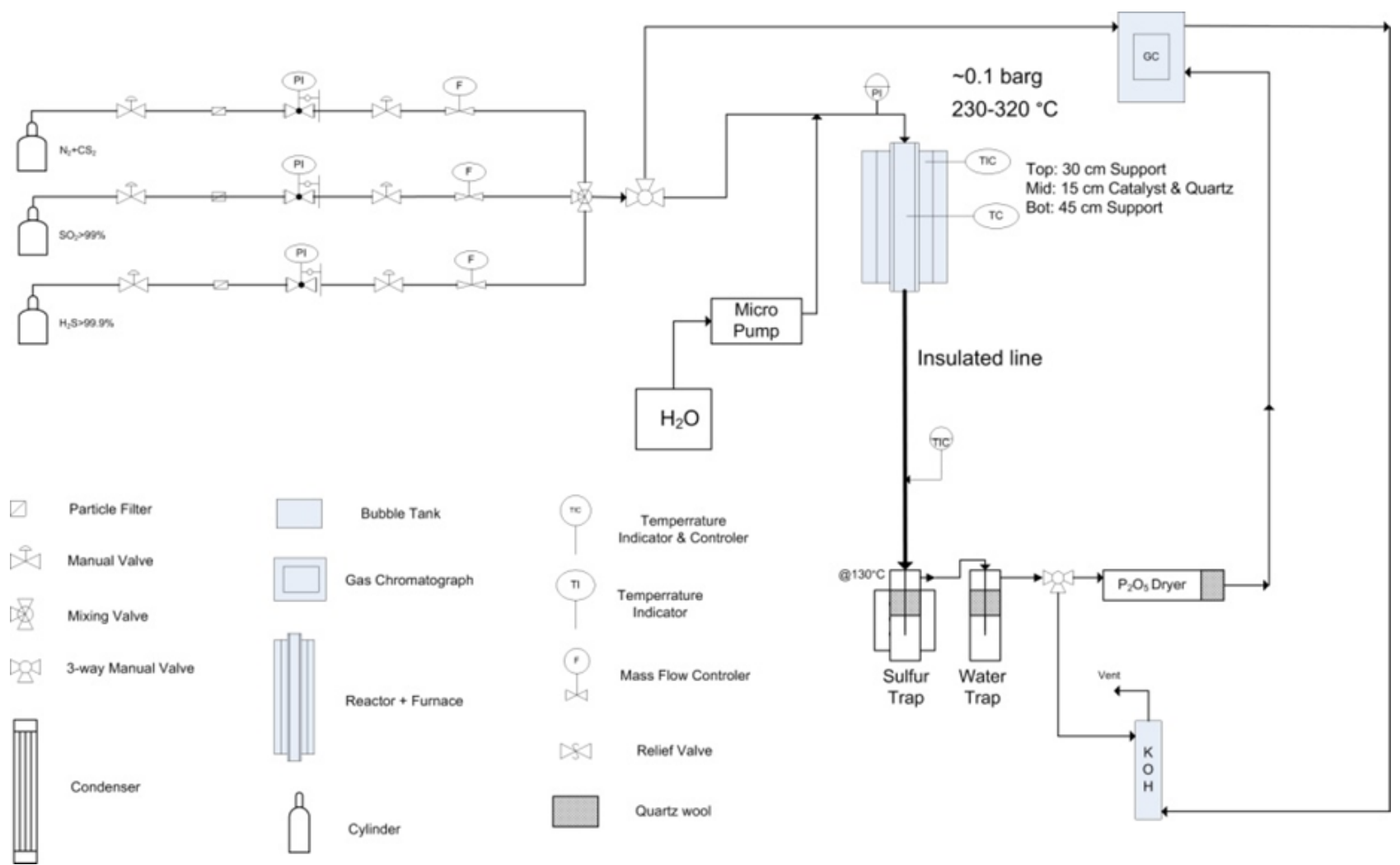

Figure 2. Schematic flow diagram of the bench scale Claus reactor [20]. 
was confirmed that with an acceptable error, it could certainly predict the $\mathrm{H}_{2} \mathrm{~S}$ and $\mathrm{CS}_{2}$ conversions. The following assumptions were presumed in this model: the reactor works in plug flow regime, activity of Claus catalysts do not vary, the reactor is isotherm, and both feed and product streams behave such an ideal gas.

Therefore, rate constants for Equations (1) to (3) were written as follows [12]:

Forward path of the main Claus reaction:

$$
r_{H_{2} S}(1)=-k_{1} \frac{C_{H_{2} S} S_{S O_{2}}^{0.5}}{\left(1+K_{5} C_{H_{2}}\right)^{2}}
$$

Backward path of the main Claus reaction:

$$
r_{\mathrm{H}_{2} \mathrm{O}}(1)=-k_{2} C_{\mathrm{H}_{2} \mathrm{O}} C_{s n}^{n s 1}
$$

And, second \& third reactions corresponding to $\mathrm{CS}_{2}$ conversion:

$$
\begin{aligned}
& r_{C_{2}}(2)=-k_{3} C_{C S_{2}}^{0.5} C_{\mathrm{H}_{2} \mathrm{O}} \\
& r_{C S_{2}}(3)=-k_{4} C_{\mathrm{CS}_{2}} C_{\mathrm{SO}_{2}}
\end{aligned}
$$

Besides, kinetic constants of the model were expressed as follows:

$$
\begin{aligned}
& k_{1}=k_{01} \exp \left(-E_{1} / R T\right) \\
& k_{2}=k_{1} / K_{p} \\
& k_{3}=k_{03} \exp \left(-E_{3} / R T\right) \\
& k_{4}=k_{04} \exp \left(-E_{4} / R T\right) \\
& \log K_{p}(T)=\frac{5910}{T}+1.13 \times 10^{-3} T-1.038 \times \ln (T)
\end{aligned}
$$

By considering an infinitesimal volume of catalyst inside the reactor, the mass conservation was expressed as:

$$
\left.Q C_{i}\right|_{V+d V}-\left.Q C_{i}\right|_{V} \pm R_{i} . \partial V=\frac{\partial\left(\partial V \cdot C_{i}\right)}{\partial t_{r}}
$$

And consequently, this equation can be asserted as follows:

$$
\begin{aligned}
& \frac{\partial C_{i}}{\partial V}=\frac{R_{i} \rho_{\text {ave }}}{m_{f}} \\
& \frac{1}{\rho_{\text {ave }}}=\sum \frac{x_{m, i}}{\rho_{i}} \\
& \frac{\partial P_{i}}{\partial V}=R_{g} T\left(\frac{R_{i} \rho_{\text {ave }}}{m_{f}}\right)
\end{aligned}
$$

In Equation (17), $R_{i}$ is the reaction rate of all components i.e. $\mathrm{CS}_{2}, \mathrm{H}_{2} \mathrm{O}, \mathrm{SO}_{2}, \mathrm{H}_{2} \mathrm{~S}, \mathrm{~N}_{2}$ and sulfur through the catalytic bed which was formulated as:

$$
\begin{aligned}
& R_{C S_{2}}=r_{C S_{2}}(2)+r_{C S_{2}}(3) \\
& R_{\mathrm{H}_{2} \mathrm{O}}=2 r_{C S_{2}}(2)-r_{\mathrm{H}_{2} \mathrm{~S}}(1)+r_{\mathrm{H}_{2} \mathrm{O}}(1) \\
& R_{\mathrm{SO}_{2}}=r_{C S_{2}}(3)+0.5 r_{\mathrm{H}_{2} \mathrm{~S}}(1)-0.5 r_{\mathrm{H}_{2} \mathrm{O}}(1) \\
& R_{\mathrm{H}_{2} \mathrm{~S}}=-2 r_{C S_{2}}(2)+r_{\mathrm{H}_{2} \mathrm{~S}}(1)-r_{\mathrm{H}_{2} \mathrm{O}}(1) \\
& R_{\mathrm{N}_{2}}=0 \\
& R_{S}=-\frac{3}{n} r_{C S_{2}}(3)-\frac{1.5}{n} r_{\mathrm{H}_{2} \mathrm{~S}}(1)+\frac{1.5}{n} r_{\mathrm{H}_{2} \mathrm{O}}(1) \\
& R_{C \mathrm{O}_{2}}=-r_{C S_{2}}(2)-r_{C S_{2}}(3)
\end{aligned}
$$

Kinetic coefficients corresponding to the studied $\mathrm{Al}_{2} \mathrm{O}_{3}$ and $\mathrm{TiO}_{2}$ catalysts (Table 2) are presented in Table 3 [20]. Moreover, XRD analysis of the sulfur produced by Claus catalysts proved that sulfur allotropes have eight atoms of sulfur (S8) which is consistent with the other research [21]. Therefore, the stoichiometric coefficients of sulfur in the kinetic model of $\mathrm{Al}_{2} \mathrm{O}_{3}$ and $\mathrm{TiO}_{2}$ catalysts (i.e. $n$ in Equa-

\begin{tabular}{|c|c|c|}
\hline Kinetic parameter & $\mathrm{Al}_{2} \mathrm{O}_{3}$ & $\mathrm{TiO}_{2}$ \\
\hline $\begin{array}{c}k_{01} \\
\left(\mathrm{~m}^{3} /\left(\mathrm{cm}^{3} \mathrm{cat} \cdot \mathrm{h} . \mathrm{kmol}^{0.5}\right)\right)\end{array}$ & $1.36 \times 10^{-7}$ & $15.94 \times 10^{5}$ \\
\hline$E_{1}(\mathrm{kcal} / \mathrm{mol})$ & 7.64 & 25.05 \\
\hline $\begin{array}{c}k_{03} \\
\left(\mathrm{~m}^{3} /\left(\mathrm{cm}^{3} \text { cat.h.kmol }{ }^{0.5}\right)\right)\end{array}$ & $123.17 \times 10^{3}$ & $97.49 \times 10^{3}$ \\
\hline$E_{3}(\mathrm{kcal} / \mathrm{mol})$ & 12.12 & 8.68 \\
\hline $\begin{array}{c}k_{04} \\
\left(\mathrm{~m}^{3} /\left(\mathrm{cm}^{3} \text { cat.h.kmol }\right)\right)\end{array}$ & 29.13 & 16.81 \\
\hline $\mathrm{E}_{4}(\mathrm{kcal} / \mathrm{mol})$ & 3.5 & 3.5 \\
\hline$K_{5}$ & 87.05 & 218.69 \\
\hline $\mathrm{ns} 1$ & 0 & 0 \\
\hline
\end{tabular}
tions 1 and 3) are equal to eight.

In the current study, to develop the multilayer model for the bench scale reactor, two distinguished subroutines were constructed for $\mathrm{Al}_{2} \mathrm{O}_{3}$ and $\mathrm{TiO}_{2}$ layers. These functions were named Alumina_model and Titania_model, respectively. Hence, Equations (5) to (24) for each layer in conjunction with its corresponding kinetic parameters (Table 3) were implemented and solved in MATLAB programming interface (MathWorks, 2013). As seen in Figure 3, the feed of the Claus converter (Table 1) is injected to the Alumina subroutine. The product of the $\mathrm{Al}_{2} \mathrm{O}_{3}$ bed is calculated by the Alumina_model, and then it is introduced to the Titania section. Finally, the output of the multilayer catalytic bed is determined by the Titania_model.

Table 3. Kinetic parameters estimated for the $\mathrm{Al}_{2} \mathrm{O}_{3}$ and $\mathrm{TiO}_{2}$ commercial catalysts [20]. 
2.3.2 Kinetic model for the industrial scale reactor

To develop an adiabatic model in this research, by assuming a variable cross section area $(A)$ along the $\mathrm{x}$-direction of the horizontal reactor (see Figure 4), Equation (17) can be expressed as below:

$$
\frac{\partial P_{i}}{\partial x}=A \times R \times T\left(\frac{R_{i} \cdot \hat{\rho}}{m_{f}}\right)
$$

But, the area cross section of the reactor is sum of the area of the cylindrical (A1) and torispherical (A2) sections of the reactor. According to the Figures 5 and 6 , these variables are expressed as follows [22]:

$$
\begin{aligned}
& \theta=\cos ^{-1}(1-x / R) \\
& l=2 R \sin \theta \\
& A_{1}=L R \times l \\
& z=R_{C}-\sqrt{\left(R_{C}-R_{k}\right)^{2}-\left(\frac{D_{e x t}}{2}-t-R_{k}\right)^{2}} \\
& D_{e x t}=2 \times R+t \\
& R_{k}=3 \times t
\end{aligned}
$$

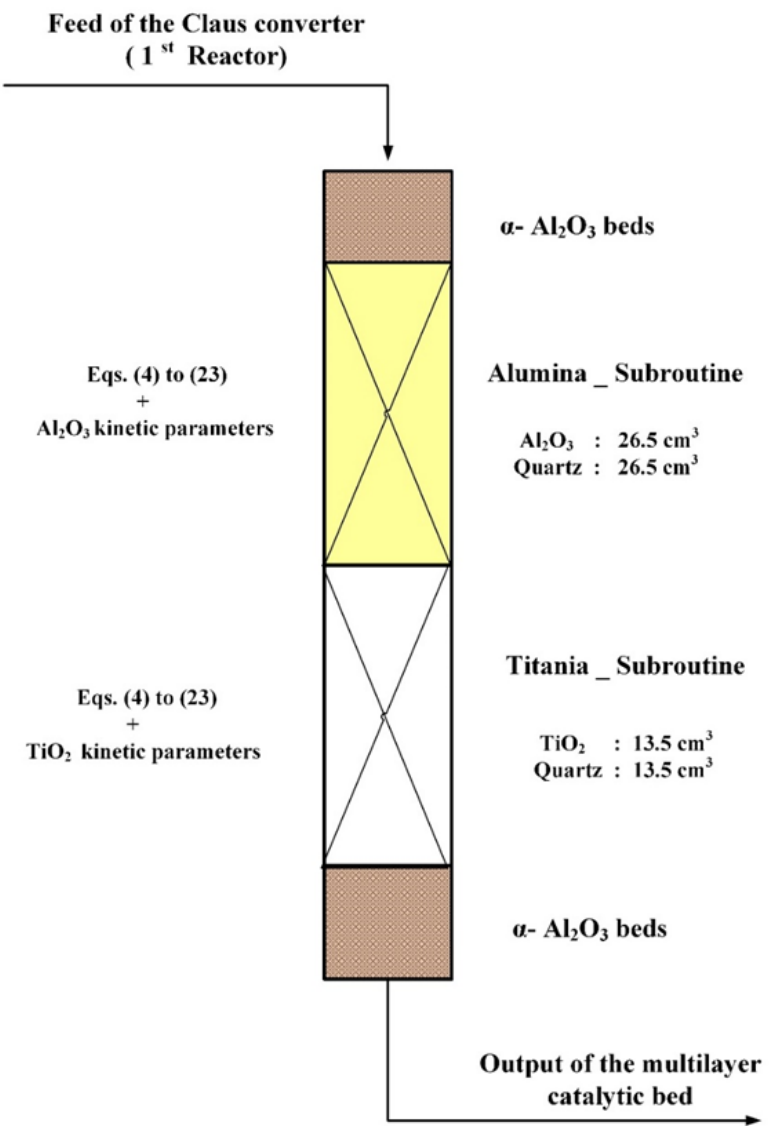

Figure 3. Diagram of the multilayer Claus bed model.

$$
\begin{aligned}
& \tan \alpha_{1}=\frac{z}{R} \\
& z_{1}=x \times \tan \alpha_{1} \\
& z_{1}=(2 R-x) \times \tan \alpha_{1} \\
& A_{2}=z_{1} \times l \\
& A=A_{1}+2 A_{2}
\end{aligned}
$$

For the understudy Claus reactor, the values of fixed variables including $R, L R$, and $t$, are $1.925 \mathrm{~m}, 6 \mathrm{~m}$ and $0.15 \mathrm{~m}$, respectively. Finally, to find the temperature profile along the catalytic bed, the heat balance equation is expressed as follows:

$$
\frac{d T}{d V}=\frac{U A_{e x t}\left(T_{e x t}-T\right)+\sum_{i=1}^{m}\left(-r_{i}\right)\left(-\Delta H_{r_{i}}\right)}{\sum_{j=1}^{n} m_{f, j} C_{p, j}}
$$

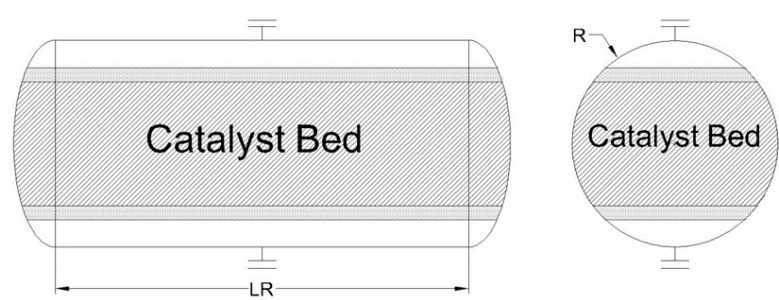

Figure 4. Horizontal view of the industrial scale Claus reactor.

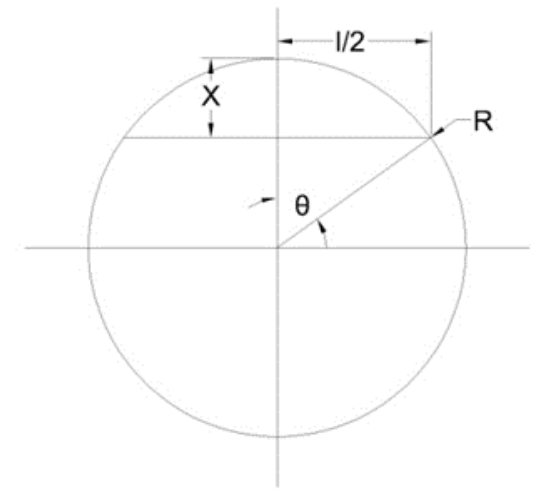

Figure 5. Cross-section of the industrial scale Claus reactor.

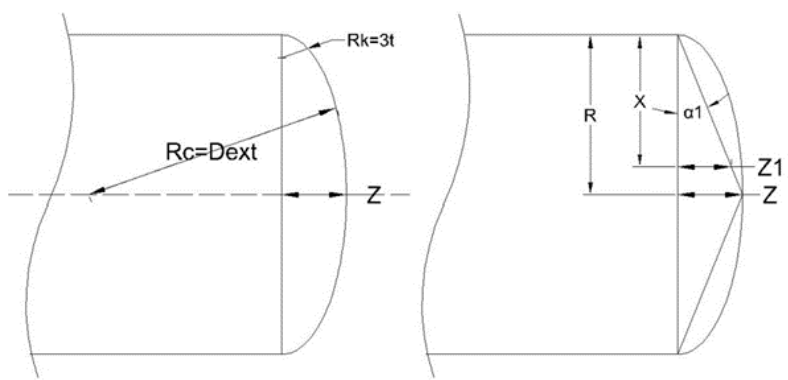

Figure 6. Torispherical head of the industrial scale Claus reactor. 
Because of insulating the Claus reactor, it is assumed that the overall heat transfer coefficient $(U)$ is equal to zero. Therefore, there is no heat transfer between the wall of the vessel and the environment, and the converter can be modeled as an adiabatic reactor. To develop the industrial scale adiabatic model, Equations (5) to (37) were implemented in Matlab environment (MathWorks, 2013a), and similar to the bench scale multi-layer (combined bed) model, they were sequentially solved for $\mathrm{Al}_{2} \mathrm{O}_{3}$ and $\mathrm{TiO}_{2}$ catalytic layers using the corresponding kinetic parameters (Table 3), fixed variables of the industrial scale Claus Converter (dimensions of converter and volume of catalysts), and actual operating conditions (GHSV and composition and temperature of feed).

\section{Results and Discussions}

\subsection{Evaluating the Bench Scale Claus Reactor}

The temperature of the bench scale reactor is set on the weighted average bed temperature (WABT) of the industrial scale plant (equal to $289^{\circ} \mathrm{C}$ ). The $\mathrm{GHSVs}$ of $\mathrm{Al}_{2} \mathrm{O}_{3}$ and $\mathrm{TiO}_{2}$ catalytic beds are set on actual values equal to $1051.9 \mathrm{~h}^{-1}$ and $2105.5 \mathrm{~h}^{-1}$, respectively. According to results obtained from the proposed combined bed model, it is found that molar percentages of $\mathrm{H}_{2} \mathrm{~S}$ and $\mathrm{CS}_{2}$ in the output stream of the bench scale reactor are $1.28 \%$ and $0.14 \%$, respectively. Based on data gathered from the industrial scale reactor, these values should reach 1.61 $\mathrm{mol} \%$ and $0.02 \mathrm{~mol} \%$, respectively in the product of the first converter. Therefore, it is discovered that evaluating a multilayer Claus bed (isothermal reactor) at the WABT of an adiabatic converter cannot accurately reveal the behavior of Claus catalysts in a combined bed configuration. It is supposed that this discrep-

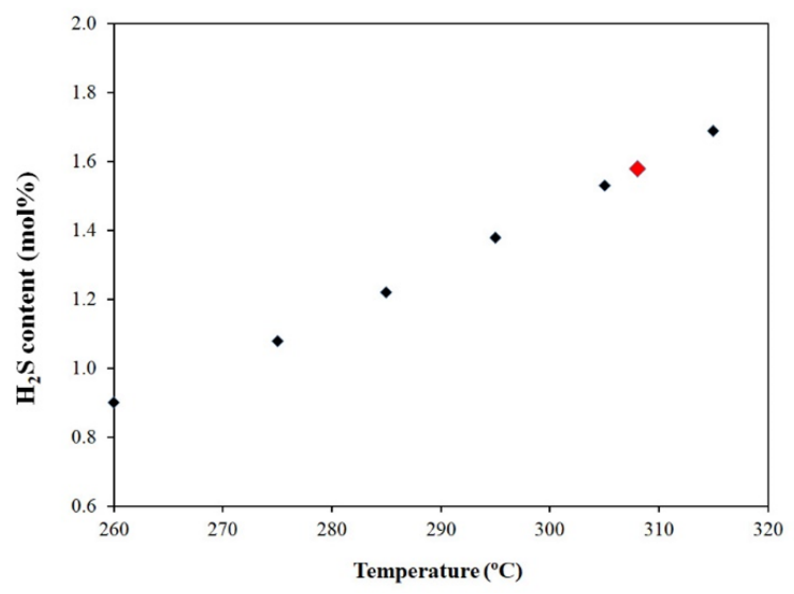

Figure 7. $\mathrm{H}_{2} \mathrm{~S}$ content of product versus temperature of the bench scale reactor. ancy can be related to the difference in hydrodynamic regime and non-linearity of the system.

To find a better temperature for the bench scale equipment, variations of $\mathrm{H}_{2} \mathrm{~S}$ and $\mathrm{CS}_{2}$ contents of the product versus bed temperature are presented in Figures 7 and 8, respectively. As seen, by increasing this variable, the $\mathrm{H}_{2} \mathrm{~S}$ content increases due to the exothermic and reversible nature of the main Claus reaction (Equation 1). Conversely, temperature has a negative effect on the $\mathrm{CS}_{2}$ content of the product. Furthermore, as observed in Figure 8, $\mathrm{CS}_{2}$ is effectively converted at the temperatures higher than $290{ }^{\circ} \mathrm{C}$ because of high activity of titania layer at the elevated temperatures [23]. In this layer, $\mathrm{CS}_{2}$ conversion is corresponded to the reactions with both $\mathrm{SO}_{2}$ and $\mathrm{H}_{2} \mathrm{O}$ (Equations 2 and 3), and therefore both reactions are active over the titania catalyst.

It is supposed that the relation between the $\mathrm{CS}_{2}$ conversion and temperature of the catalytic bed is nonlinear due to the different activities of titania catalyst at low and high temperatures. Hence, if evaluation of the multilayer catalyst is carried out at the WABT (equal to $289^{\circ} \mathrm{C}$ ), the titania catalyst is not effectively active, and the $\mathrm{CS}_{2}$ conversion is definitely lower than the actual value observed in an industrial scale reactor. In contrast, in this layer due to the exothermic nature of the main Claus reaction (i.e. Equation 1), $\mathrm{H}_{2} \mathrm{~S}$ is efficiently converted to sulfur, and therefore its conversion is obviously higher than the expected value in a commercial scale converter. Thus, as seen in Figures 7 and 8 , at the bed temperature of about $307{ }^{\circ} \mathrm{C}$ (higher than WABT), $\mathrm{H}_{2} \mathrm{~S}$ and $\mathrm{CS}_{2}$ contents of the outlet stream can meet their actual values expected in a commercial scale SRU at the start of run (SOR).

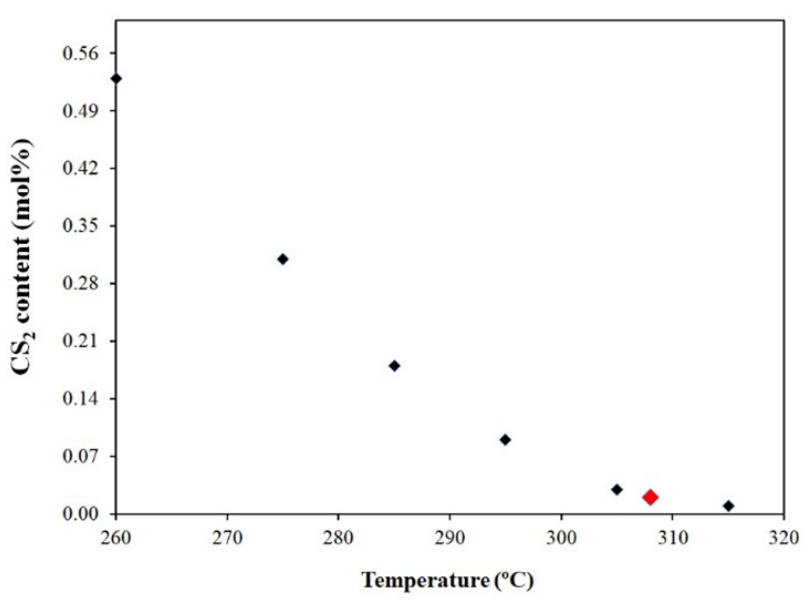

Figure 8. $\mathrm{CS}_{2}$ content of product versus temperature of the bench scale reactor. 
In Figure 9, variations of $\mathrm{CS}_{2}$ and $\mathrm{H}_{2} \mathrm{~S}$ mole percentages along the multilayer catalytic bed at the temperature of $307{ }^{\circ} \mathrm{C}$ is depicted. As seen, the slope of the curve for $\mathrm{TiO}_{2}$ layer (from $26.5 \mathrm{~cm}^{3}$ to $40 \mathrm{~cm}^{3}$ ) is larger than that of $\mathrm{Al}_{2} \mathrm{O}_{3}$ catalytic layer (from 0 to $26.5 \mathrm{~cm}^{3}$ ). This phenomenon proves that $\mathrm{TiO}_{2}$ catalyst has considerably higher affinity to convert and hydrolyze carbon-sulfur compounds than $\mathrm{Al}_{2} \mathrm{O}_{3}$ catalyst, and if the converter is totally loaded with the latter catalyst, the carbon-sulfur content of the tail gas will not meet the requirements. Additionally, Figure 9 illustrates the generation of $\mathrm{H}_{2} \mathrm{~S}$ through $\mathrm{TiO}_{2}$ layer because of promoting the reverse Claus reaction (see Equation 1). Therefore, to compensate the $\mathrm{H}_{2} \mathrm{~S}$ production through this layer, implementing at least a reactor after the first converter is essentially needed. It should be recalled that approximately all carbon-sulfur compounds are depreciated through the first converter, and therefore the temperature of the second reactor can be reduced up to the dew point of the elemental sulfur. Therefore, $\mathrm{H}_{2} \mathrm{~S}$ conversion increases because of the exothermic nature of the main Claus reaction. However, if the temperature reaches the values lower than sulfur dew point temperature, it is cultivated, and fills the pores of the catalyst. Consequently, Claus catalysts are encountered with an accelerated deactivation [24,25].

\subsection{Scale Up the Bench Scale Claus Reactor}

The adiabatic model is run by using actual operating conditions (i.e. feed temperature of $235{ }^{\circ} \mathrm{C}$, feed composition of Table 1 , and feed flow rate of $1225.06 \mathrm{kmol} / \mathrm{h}$ ), dimensions of Claus converter and actual volume of catalysts
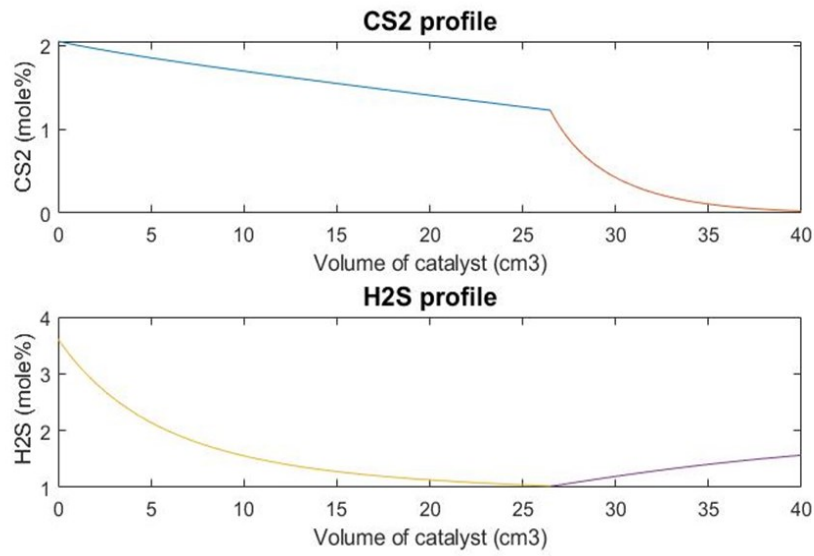

Figure 9. $\mathrm{CS}_{2}$ and $\mathrm{H}_{2} \mathrm{~S}$ profiles through the catalytic bed of bench scale Claus reactor at $\mathrm{T}=307$ ${ }^{\circ} \mathrm{C}$. (belongs to R-101). Based on results presented in Table 5, one can conclude that the developed adiabatic model is able to calculate the gas concentrations and the output flow temperature of the target reactor with a reliable accuracy. Moreover, it is observed that mole percentages of $\mathrm{CS}_{2}$ and $\mathrm{H}_{2} \mathrm{~S}$ in the exhaust gas, obtained by the model, is lower and higher than the actual values, respectively. It is supposed that the main source of this error is soaring the activity of catalyst at the initiation, causing a higher conversion for $\mathrm{CS}_{2}$ compound. As the result, the temperature rises, and the backward path of main Claus reaction is strengthened due to its exothermic nature. Thus, $\mathrm{H}_{2} \mathrm{~S}$ is generated through $\mathrm{TiO}_{2}$ catalytic layer [20]. Another reason for this deviation is to model Claus reactor as an adiabatic system. Hence, due to transferring heat from the surface of the converter to the environment, there is an inevitable positive error for the outlet temperature computed by the adiabatic model.

Besides, the mole percentages of $\mathrm{H}_{2} \mathrm{~S}$ and $\mathrm{CS}_{2}$ through the catalytic bed (x-direction) are presented in Figures 10 and 11, respectively. As seen, $\mathrm{H}_{2} \mathrm{~S}$ content of the feed decreases through the first layer of the catalytic bed (i.e. $\mathrm{Al}_{2} \mathrm{O}_{3}$ ); however, through the second layer (i.e. $\mathrm{TiO}_{2}$ ), it goes up due to rising the bed temperature and promoting the backward main Claus reaction (see Equation 1). Hence, it is essential to implement another catalytic converter after the first one working at the lower temperatures to efficiently convert $\mathrm{H}_{2} \mathrm{~S}$ in SRUs for satisfying the environmental regulations of gas

Table 4. $\mathrm{H}_{2} \mathrm{~S}$ and $\mathrm{CS}_{2}$ content of the product stream.

\begin{tabular}{cccc}
\hline $\begin{array}{c}\text { Component } \\
(\text { mol\%) }\end{array}$ & $\begin{array}{c}\text { Industrial } \\
\text { scale }\end{array}$ & $\begin{array}{c}\text { Bench } \\
\text { scale } \\
\text { @ } 289^{\circ} \mathrm{C}\end{array}$ & $\begin{array}{c}\text { Bench } \\
\text { scale } \\
\text { @ } 307^{\circ} \mathrm{C}\end{array}$ \\
\hline $\mathrm{H}_{2} \mathrm{~S}$ & 1.61 & 1.28 & 1.58 \\
$\mathrm{CS}_{2}$ & 0.02 & 0.14 & 0.02 \\
\hline
\end{tabular}

Table 5. Comparison between the actual values and model outputs for the target industrial scale Claus reactor.

\begin{tabular}{lcc}
\hline \multicolumn{1}{c}{ Parameter } & $\begin{array}{c}\text { Actual } \\
\text { value }\end{array}$ & $\begin{array}{c}\text { Adiabatic } \\
\text { model }\end{array}$ \\
\hline $\begin{array}{l}\text { Reactor temperature } \\
\left({ }^{\circ} \mathrm{C}\right)\end{array}$ & 307.6 & 315.1 \\
$\begin{array}{l}\mathrm{H}_{2} \mathrm{~S} \text { in product } \\
\left(\mathrm{mol}^{\prime}\right)\end{array}$ & 1.61 & 1.99 \\
$\begin{array}{l}\mathrm{CS}_{2} \text { in product } \\
(\mathrm{mol} \%)\end{array}$ & 0.118 & 0.002 \\
\hline
\end{tabular}


emission. Furthermore, Figure 10 demonstrates that at the $\mathrm{SOR}$, a part of $\mathrm{Al}_{2} \mathrm{O}_{3}$ catalytic layer (from $158 \mathrm{~cm}$ to $196 \mathrm{~cm}$ ) does not play a significant role in boosting $\mathrm{H}_{2} \mathrm{~S}$ conversion. However, commercial $\mathrm{Al}_{2} \mathrm{O}_{3}$ Claus catalysts, hastily lose their activity versus time [26], and therefore this excess volume of catalyst is reserved to repay the loss of catalyst activity versus process time (life of the commercial $\mathrm{Al}_{2} \mathrm{O}_{3}$ catalyst is about three years).

As presented in Figure 11, the $\mathrm{CS}_{2}$ conversion is mainly boosted by the second layer of the catalytic bed (about $195 \mathrm{~cm}$ to $240 \mathrm{~cm}$ ), and converting carbon-sulfur compounds will not promote without providing $\mathrm{TiO}_{2}$ catalyst at the bottom of the Claus converter. Additionally, similar to the $\mathrm{Al}_{2} \mathrm{O}_{3}$ catalyst, an excess amount of $\mathrm{TiO}_{2}$ catalyst is granted for this layer; however, the deactivation rate of $\mathrm{TiO}_{2}$ catalyst is lower (life of the commercial $\mathrm{TiO}_{2}$ catalyst is about seven years). Therefore, the height of the excess layer is less than $15 \mathrm{~cm}$ (from about 225 $\mathrm{cm}$ to $240 \mathrm{~cm}$ ).

In Figure 12, variations in the profile of the temperature along the length of the catalytic

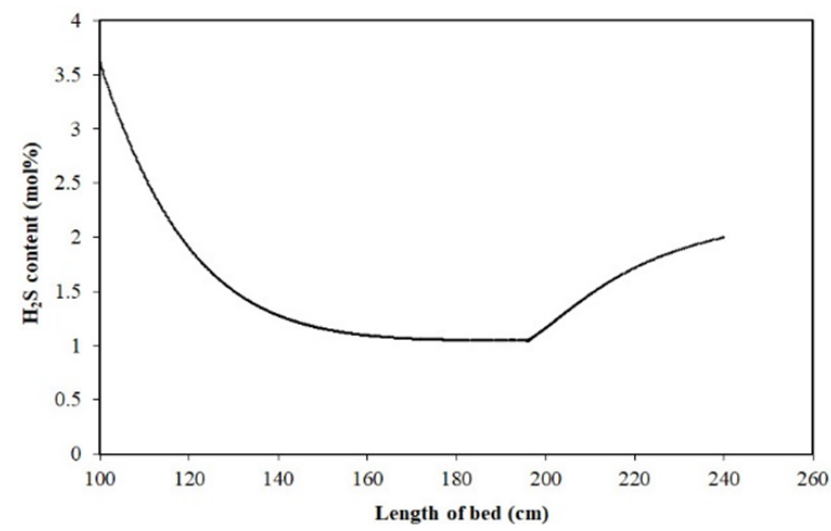

Figure 10. $\mathrm{H}_{2} \mathrm{~S}$ profile through the catalytic bed of Claus converter.

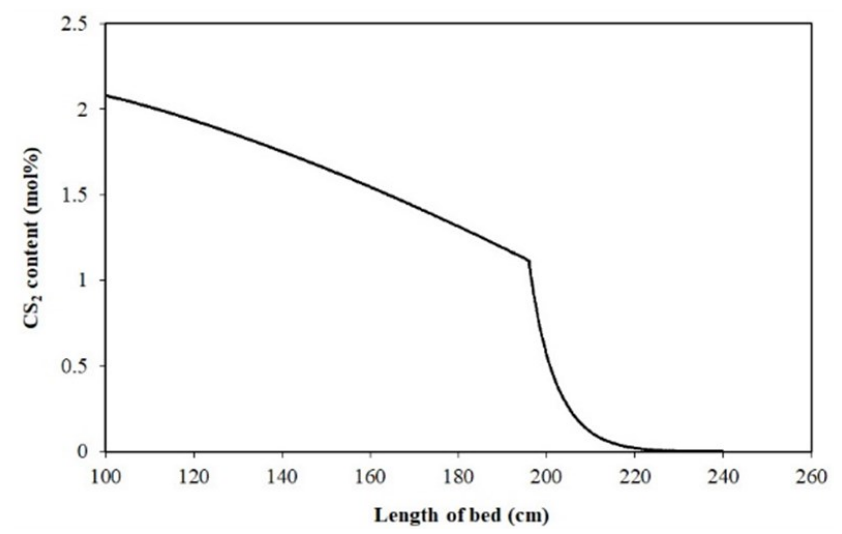

Figure 11. $\mathrm{CS}_{2}$ profile through the catalytic bed of Claus converter. bed is presented. As seen, through the $\mathrm{Al}_{2} \mathrm{O}_{3}$ layer, the temperature increases versus $\mathrm{x}$ direction because of the exothermic nature of the main Claus reaction. Then, as seen in Figure 11, at the start of the titania layer (length of $196 \mathrm{~cm}$ ), by promoting Equations (2) and (3), $\mathrm{CS}_{2}$ of the feed which is mostly unconverted in the previous layer (alumina catalyst has low affinity to convert $\mathrm{CS}_{2}$ ) is exceedingly converted to $\mathrm{H}_{2} \mathrm{~S}, \mathrm{CO}_{2}$, and elemental sulfur. Thus, the temperature sharply increases due to the exothermic nature of Equations (1) and (3) (see Figure 12), and the probability of collision between molecules or diffusion of molecules towards active sites of the catalyst is intensified [27]. Afterwards, the rate of the backward Claus reaction (an endothermic reaction, see Equation 1) increases due to the elevated bed temperature (at the length of $210 \mathrm{~cm}$ ), and after reaching a peak, the temperature slightly decreases along the length of the Claus converter.

\section{Conclusions}

Carrying out isotherm bench scale experiments under the linearly weighted average temperature of a commercial Claus converter (i.e. WABT) imposed inaccuracy to assess activities of those catalysts. A kinetic-based multilayer Claus model confirmed that to compromise between $\mathrm{H}_{2} \mathrm{~S}$ and $\mathrm{CS}_{2}$ conversions of the isothermal bench scale reactor and those of an adiabatic Claus converter, experiments should be done at the temperature of $307^{\circ} \mathrm{C}$ instead of the WABT of $289^{\circ} \mathrm{C}$. Moreover, the industrial scale adiabatic model developed for a real Claus converter was able to calculate the temperature, and molar percentages of $\mathrm{H}_{2} \mathrm{~S}$ and $\mathrm{CS}_{2}$ of the product equal to $315.1{ }^{\circ} \mathrm{C}, 1.99 \%$, and $0.002 \%$, respectively. Based on data gathered from the target SRU, the actual values of

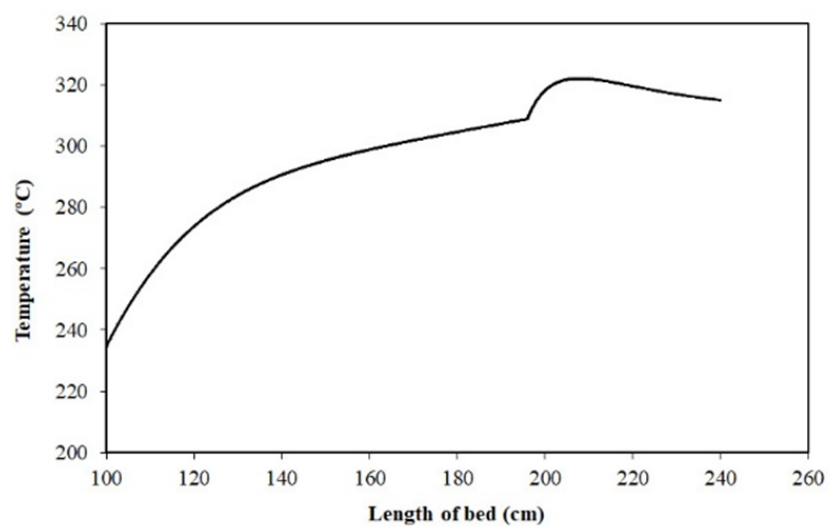

Figure 12. Temperature profile through the catalytic bed of Claus converter. 
those variables were $308{ }^{\circ} \mathrm{C}, 1.61 \mathrm{~mol} \%$, and $0.118 \mathrm{~mol} \%$, respectively. It was supposed that the main source of above deviations was the high activity of Claus catalysts during bench scale experiments. Additionally, the negligence of the heat transfer from the surface of the converter to the environment (i.e. to consider adiabatic process) exacerbated the heat increase through the catalytic bed. About $20 \%$ of the total catalyst volume was regarded to compensate the loss of catalyst activity during cycle life.

\section{Acknowledgement}

The authors gratefully acknowledge the financial support provided by National Iranian Gas Company (NIGC) and Gas Processing Institute (GPI). The authors would also like to thank Professor Farhad Khorashe from Sharif University of Technology for his role in supervision of this research work.

\section{Nomenclatures}

\begin{tabular}{|c|c|}
\hline$A$ & Reactor cross section, $\left(\mathrm{m}^{2}\right)$ \\
\hline$A_{\text {ext }}$ & Reactor external area, $\left(\mathrm{m}^{2}\right)$ \\
\hline$C_{\mathrm{i}}$ & $\begin{array}{l}\text { Concentration of component } i, \\
\left(\mathrm{kmol}^{-3}\right)\end{array}$ \\
\hline$C_{\mathrm{pj}}$ & 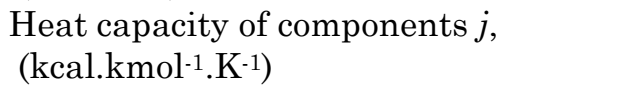 \\
\hline$D_{\text {ext }}$ & Reactor external diameter, $(\mathrm{m})$ \\
\hline$E_{\mathrm{i}}$ & $\begin{array}{l}\text { Activation energy of } i^{\text {th }} \text { reaction, } \\
\left(\text { kcal.mol-1) }^{-1}\right.\end{array}$ \\
\hline$K_{5}$ & $\begin{array}{l}\text { Coefficient of the adsorption term in } \\
\text { the main Claus reaction }\end{array}$ \\
\hline$k_{0 \mathrm{i}}$ & Frequency factor of $i^{\text {th }}$ reaction \\
\hline$k_{\mathrm{i}}$ & Reaction rate constant of component $i$ \\
\hline$K_{\mathrm{p}}$ & $\begin{array}{l}\text { Equilibrium constant of Claus reac- } \\
\text { tion, (-) }\end{array}$ \\
\hline$L R$ & Catalyst bed length, (m) \\
\hline$m_{\mathrm{f}}$ & Mass flow rate, $\left(\mathrm{kg} \cdot \mathrm{h}^{-1}\right)$ \\
\hline$n s i$ & Reaction order, (-) \\
\hline$N_{\mathrm{t}}$ & $\begin{array}{l}\text { Number of experimental data points, } \\
(-)\end{array}$ \\
\hline$P_{\mathrm{i}}$ & Partial pressure, (atm) \\
\hline$Q$ & Volume flow rate, $\left(\mathrm{m}^{3} \cdot \mathrm{h}^{-1}\right)$ \\
\hline$r_{\mathrm{i}}$ & $\begin{array}{l}\text { Reaction rate of component } i \text {, } \\
\left(\mathrm{kmol}^{-1} \cdot \mathrm{hg} \mathrm{cat}^{-1}\right)\end{array}$ \\
\hline$R$ & Radius of the reactor, (m) \\
\hline$R_{\mathrm{c}}$ & Reactor inside crown radius, (m) \\
\hline$R_{\mathrm{g}}$ & Gas constant, (kcal/kmol.K) \\
\hline$R_{\mathrm{i}}$ & $\begin{array}{l}\text { Summation of reaction rate of all com- } \\
\text { ponents, }\left(\mathrm{kmol}^{-1} \mathrm{~h}^{-1} \cdot \mathrm{kg} \mathrm{cat}^{-1}\right)\end{array}$ \\
\hline$R_{\mathrm{k}}$ & Reactor inside knukle radius, (m) \\
\hline$T$ & Reaction temperature, $(\mathrm{K})$ \\
\hline$t$ & Thickness of vessel, $(\mathrm{m})$ \\
\hline $\operatorname{tr}$ & Reaction time, (h) \\
\hline
\end{tabular}

$T_{\text {ext }} \quad$ Ambient temperature, (K)

$U \quad$ Overall heat transfer coefficient, (kcal. $\mathrm{m}^{-2} \cdot \mathrm{K}^{-1} \cdot \mathrm{h}^{-1}$ )

$V \quad$ Catalyst bed volume, $\left(\mathrm{m}^{3}\right)$

$W A B T$ Weighted average bed temperature $\left({ }^{\circ} \mathrm{C}\right)$

$x_{\mathrm{m}, \mathrm{i}} \quad$ Mass fraction of component $i,(-)$

$Z \quad$ Depth of the reactor head, (m)

$\Delta H \quad$ Reaction heat, $\left(\mathrm{kcal}^{\mathrm{h}} \mathrm{h}^{-1}\right)$

$\rho_{\mathrm{i}} \quad$ Density of component $i,\left(\mathrm{~kg} . \mathrm{m}^{-3}\right)$

$\partial V \quad$ Volume element of catalyst bed, $\left(\mathrm{m}^{3}\right)$

pave Average density of the flow through the catalytic bed at the reaction temperature, $\left(\mathrm{kg} \cdot \mathrm{m}^{-3}\right)$

\section{References}

[1] Nawaf, A.T., Jarullah, A.T., Abdulateef, L.T. (2019). Design of a Synthetic Zinc Oxide Catalyst over NanoAlumina for Sulfur Removal by Air in a Batch Reactor. Bulletin of Chemical Reaction Engineering \& Catalysis, 14(1): 79-92.

[2] Zarei, S. (2018). A Review of Investigations on Claus Reaction Furnace of Sulfur Recovery Unit. COJ Technical Scientific Research, 1(3): $1-3$.

[3] Tasdemir, H.M. (2019). The Catalytic Activity Enhancement of Commercial $\mathrm{TiO}_{2}$ and $\mathrm{Nb}_{2} \mathrm{O}_{5}$ Catalysts by Iron for Elemental Sulfur Production from $\mathrm{H}_{2} \mathrm{~S}$. Catalysis letters, 149(2): 473-485.

[4] Nagamalleswara R.K., Haydary. J. (2019). Studies on Sulfur Recovery Plant Performance Using Aspen Hysys Sulsim Simulation. Petroleum \& Coal, 61(2): 292305.

[5] Zarei, S. (2018). A Modified Kinetic Reaction Scheme for Claus Reaction Furnaces in Oil Refineries. Innovative Energy \& Research. 7(3): 2-9.

[6] ZareNezhad, B. (2009). An investigation on the most important influencing parameters regarding the selection of the proper catalysts for Claus SRU converters. Journal of Industrial and Engineering Chemistry, 15(2): 143-147.

[7] Clark, P.D., Dowling, N.I., Huang, M. (2008). Reversible deactivation of $\mathrm{TiO}_{2}$ in $\mathrm{CS}_{2}$ conversion associated with Claus reaction. Applied Catalysis A: General, 8(343): 104-108.

[8] Kerr, R.K., Paskal, H.G., Ballash, N. (1976). Claus Process: Catalytic Kinetics Part 1Modified Claus Reaction. Energy Processing (Canada), Sept.-Oct: 66-72.

[9] Kerr, R.K., Paskal, H.G. (1976). Claus Process: Catalytic Kinetics Part 2- COS and 
$\mathrm{CS}_{2}$ Hydrolysis. Energy Processing (Canada), Nov.-Dec.: 38-44.

[10] Kerr, R.K., Paskal, H.G., Ballash, N. (1977). Claus Process: Catalytic Kinetics Part 3Deactivation Mechanisms Evaluation and Catalyst. Energy Processing (Canada), Jan.Feb.: 40-51.

[11] Mendioroz, S., Munoz, V., Alvarez, E., Palacios, J.M. (1995). Kinetic study of the Claus reaction at low temperature using $\mathrm{Y}^{-}$ alumina as catalyst. Applied Catalysis A: General, 132 (1): 111-126.

[12] Nedez, C., Ray, J.L. (1997). Understanding Claus catalyst deactivation mechanisms: Optimization of $\mathrm{Al}_{2} \mathrm{O}_{3}$ using physic-chemical parameters, Catalyst Deactivation, ed. by C.H. Bartholomew and G.A. Fuentes, Elsevier Science, pp. 251-258.

[13] Zagoruiko, A.N., Matros, Y.S. (2002). Mathematical modeling of Claus Reactors Undergoing Sulfur Condensation and Evaporation. Chemical Engineering Journal, 87: 73-88.

[14] Gemmingen, U., Lahne, U. (1994). The Linde Clinsulf ${ }^{\circledR}$ process for sulfur recovery: Modelling and simulation. Gas Separation \& Purification, 8: 241-246.

[15] Abedini, R., Koolivand, M., Ghasemian, S. (2010). Modeling and Simulation of Condensed Sulfur in Catalytic Beds of Claus Process: Rapid Estimation. Chemical Engineering Research Bulletin, 14: 110-114.

[16] Nabikandi, N.J., Fatemi, S. (2015). Kinetic modelling of a commercial sulfur recovery unit based on Claus straight through process: Comparison with equilibrium model. Journal of Industrial and Engineering Chemistry, 30: 50-63.

[17] Ghahraloud, H., Farsi, M., Rahimpour, M.R. (2017). Modeling and optimization of an industrial Claus process: Thermal and catalytic section. Journal of the Taiwan Institute of Chemical Engineers, 76: 1-9.

[18] Ghahraloud, H., Farsi, M., Rahimpour, M.R. (2018). Modification of Claus Sulfur Recovery Unit by Isothermal Reactors to Decrease Sulfur Contaminant Emission: Process Modeling and Optimization. Chemical Product and Process Modeling, 14(2): 1-12.
[19] Sadigh, S., Mohaddecy, S.R. (2018). Process Simulation and Optimization of Catalytic Reactors of Sulfur Recovery Unit (SRU) via Aspen Plus. Petroleum and Coal, 60(1): 71-78.

[20] Sadigh, S, Mohaddecy, S.R., Rashidzadeh, M., Nooriasl, P. (2020). Kinetic-based Models for Alumina and Titania Claus Catalysts Based on Experimental Data. Petroleum Chemistry, 60(3): 321-328.

[21] Abdel-Fattah, A., Seif-Eddeen, K.F., Tarek, M.M., Fouad Mai, M.K. (2016). ThreeDimensional CFD Simulation of Industrial Claus Reactors. Chemical Engineering Research and Design, 112: 78-87.

[22] Barderas, A.V., Stephania, B.S., Roda, G. (2016). How to calculate the volumes of partially full tanks. International Journal of Research in Engineering and Technology, 5: 1-7.

[23] Clark, P.D., Dowling, N.I., Huang, M. (2001). Conversion of $\mathrm{CS}_{2}$ and COS over Alumina and Titania under Claus Process Conditions: Reaction with $\mathrm{H}_{2} \mathrm{O}$ and $\mathrm{SO}_{2}$. Applied Catalysis B: Environmental, 31: 107-112.

[24] Khanaev, V.M., Borisova, E.S., Kalinkin, P.N., Kovalenko, O.N. (2018). Effect of the Porous Structure of a Catalyst on the Rate of Its Deactivation in the Claus Reaction. Theoretical foundations of Chemical Engineering, 52(4): 506-513.

[25] Istadi, I., Anggoro, D.D., Amin, N.A.S., Ling, D.H.W. (2011). Catalyst deactivation simulation through carbon deposition in carbon dioxide reforming over $\mathrm{Ni} / \mathrm{CaO}-\mathrm{Al}_{2} \mathrm{O}_{3}$ catalyst. Bulletin of Chemical Reaction Engineering \& Catalysis, 6 (2), 129-136. DOI: 10.9767/bcrec.6.2.1213.129-136

[26] Platonov, O.I. (2019). Lifetime of Alumina Catalysts in the Claus Reactor during Sulfur Removal from Coke-Oven Gas. Coke \& Chemistry, 62(3): 23-17.

[27] Patan, A.K., Mekala, M., Thamida, S.K. (2018). Dynamic Simulation of Heterogeneous Catalysis at Particle Scale to Estimate the Kinetic Parameters for the Pore Diffusion Model. Bulletin of Chemical Reaction Engineering \& Catalysis, 13(3): 420-428. 